\begin{tabular}{l} 
Hydrogen has become the subject of atten- \\
tion as an environmentally friendly and effective \\
source in recent years. The photocatalysis meth- \\
od with biomass-photocatalyst is an alternative \\
step for hydrogen production via water split- \\
ting. In this study, bamboo charcoal (BC) and \\
Fragaria Vesca Powder (FVP) are biomass mate- \\
rials used to develop photocatalysts in hydrogen \\
production. The light source for photocatalysis \\
was a halogen lamp with a wavelength of 560 nm. \\
The hydrogen gas produced is measured using \\
the MQ-8 sensor which is capable of measuring \\
hydrogen gas in $100-10,000$ ppm. Hydrogen pro- \\
duction is significantly increased with the combi- \\
nation of the BC and FVP photocatalysts. Based \\
on scanning electron microscope (SEM) image \\
analysis by Image J software, BC and FVP have \\
a negative and positive charge, respectively. The \\
aromatic carbon ring in BC has an energy gap of \\
2.48 eV whereas that in FVP has a lower energy \\
gap, 2.32 eV due to functional groups energizing \\
electron in the FVP aromatic ring. The interac- \\
tion between positive and negative charges when \\
BC and FVP are combined generates the sec- \\
ond lower energy gap in the combined catalyst, \\
1.66 eV that tends to increase electron density \\
on the catalyst surface. The more dense electrons \\
destabilize more hydrogen and covalent bonds in \\
water increasing hydrogen production by 20 times \\
from that with BC only or by 4 times from that \\
with FVP only. When aluminum foil (AF) was \\
added to the bottom of the reactor tube, the pho- \\
tocatalyst's performance was strengthened. The \\
AF material was an 8011 aluminum alloy with a \\
thickness of 0.02 mm and a diameter of 80 mm. \\
AF has two important roles, that is, accelerates \\
reduction reaction and facilitates the breaking of \\
the hydrogen and covalent bonds in water \\
Kowder, aluminum foil, biomass, hydrogen, pho- \\
tocatalysis \\
\hline
\end{tabular}

UDC 634

DOI: $10.15587 / 1729-4061.2020 .213277$

\title{
DEVELOPMENT OF BAMBOO CHARCOAL AND FRAGARIA VESCA POWDER PHOTOCATALYSTS IN HYDROGEN PRODUCTION VIA WATER SPLITTING
}

\author{
Yepy Komaril Sofi'i \\ $\mathrm{PhD}$ * \\ E-mail: yepykomaril@student.ub.ac.id \\ Eko S is wanto \\ Doctor of Mechanical Engineering* \\ E-mail: eko_s112@ub.ac.id \\ Win ar to \\ Doctor of Mechanical Engineering* \\ E-mail: winarto@ub.ac.id \\ I Nyoman Gede Wardana \\ Professor of Mechanical Engineering* \\ E-mail: wardana@ub.ac.id \\ *Department of Mechanical Engineering \\ Brawijaya University
}

Jl. Mayjend Haryono, 167, Malang, Indonesia, 65145

Received date 06.10.2020

Accepted date 06.11.2020

Published date 09.12.2020
Copyright (C) 2020, Yepy Komaril Sofi'i, Eko Siswanto, Winarto, I Nyoman Gede Wardana

This is an open access article under the CC BY license (http://creativecommons.org/licenses/by/4.0)

\section{Introduction}

The energy demand from every year has increased drastically, which comes from fossil energy mostly. The use of fossils harms the environment. Global climate change is a problem that cannot be avoided [1]. New studies have been inspired by the rising demand for clean and renewable energy, to establish novel hydrogen production techniques through water splitting $[2,3]$. Hydrogen is one of the energies that have promising potential in the future. The use of hydrogen as an environmentally friendly energy material has various benefits, such as it can be stored in various possibilities, easily converted to other forms of energy, can be produced from the water with near-zero emissions, and high efficiency [4].
The widely used methods to produce hydrogen are gasification and photocatalysis. Gasification involves partial oxidation with air or reforming with steam or carbon dioxide. Critical problems that include large amounts of nitrogen in the air reduce the hydrogen, stream, and carbon dioxide content in the product. On the other hand, hydrogen separation by gasification requires the complicated installation and high costs [5].

Therefore, a simple, efficient, and environmentally friendly method is needed. One of them is photocatalysis via water splitting. In general, photocatalysts with high crystallinity and small particle sizes are used to enhance hydrogen evolution [6]. However, making the particles to a small size requires a lot of effort. 
An alternative way is the use of biomass as a photocatalyst. Previous studies have tended to show less efficient results in hydrogen production using biomass materials. Therefore, this research aims to produce hydrogen gas with efficient biomass material.

\section{Literature review and problem statement}

The paper [7] presents the results of photocatalyst research with a semiconductor. Photocatalytic systems usually contain reactants, semiconductors, photocatalysts, photoreactors, and a supply of light to produce hydrogen. The reactants should work for photocatalysts by irradiation with UV light or visible light. Important properties of semiconductors in photocatalysis are band gap and appropriate morphology, stability, and high surface area. The most commonly used semiconductor is Titanium dioxide $\left(\mathrm{TiO}_{2}\right) . \mathrm{TiO}_{2}$ is a photocatalyst that has high absorption, long-term stability, and charge separation properties [8]. Anatase $\mathrm{TiO}_{2}$ is more often used than rutile and brookite because it has better performance for hydrogen production [9]. $\mathrm{TiO}_{2}$ has higher kinetic stability than rutile under room temperature conditions. Besides anatase has a band gap of $3.2 \mathrm{eV}$ and brookite $3.4 \mathrm{eV}$. These band gaps show anatase is more suitable at room temperature [10]. $\mathrm{TiO}_{2}$ has benefits such as excellent photocatalytic performance, easy accessibility, non-toxicity, and low price [11,12]. Besides $\mathrm{TiO}_{2}$, several types of semiconductors have been used for the production of hydrogen under UV irradiation and visible light. Among them, $\mathrm{ZnO}, \mathrm{Mo}, \mathrm{ZrO}_{2}, \mathrm{Fe}_{3} \mathrm{O}_{4}, \mathrm{Bi}_{2} \mathrm{O}_{3}, \mathrm{AgMO}_{3}(\mathrm{M}=\mathrm{V}, \mathrm{Nb}, \mathrm{Ta})$ [13-17]. However, they have disadvantages such as lower surface area, band gap width, incompatible redox potential, and the rate of electron recombination, which is not so good in maximizing photocatalytic activity [18]. A variety of developments such as surface sensitization, metal and non-metal doped, combining with co-catalysts, and manipulating carbon-based materials have been implemented to resolve these limitations [19-23].

On the other hand, biomass-derived carbon materials have been developed at this time. Biomass was obtained from rice husk [24], coconut shell [25], and bamboo charcoal (BC) [26]. Throughout recent years, biomass-based materials were used to prepare carbon nanomaterials as a renewable substitute for energy storage. Microstructural characteristics and chemical composition of biomass vary from each species. Biomass can be used as a functional carbon precursor. In terms of elements, the functional material synthesized mainly consists of carbon elements, and carbon-rich material is biomass [27].

In recent years, BC has interesting properties, including high absorption, catalysts and co-catalysts, medical electrodes, and agricultural functions. Besides, BC has a wide pore distribution from $1 \mathrm{~nm}$ to $1 \mu \mathrm{m}$. BC has several dominant pore sizes of $30,200,2,000$, and $20,000 \mathrm{~nm}$. This confirms the hierarchical pore feature of BC [28]. For the development of $\mathrm{BC}$ as biomass energy, the thermochemical process is one of the most effective and potential [29].

From previous studies, biomass photocatalysts have been used for hydrogen production. However, there are unresolved issues related to the efficiency of the hydrogen gas produced, which makes research impractical. We overcome this problem by increasing the photocatalyst activity. This can be done by engineering the recombination of electrons in the valence and conduction bands of the photocatalyst [30].

Previous studies suggested that photocatalyst biomass should be developed for hydrogen production via water split- ting. In this research, BC is used as a supporting catalyst for disrupting the balance of carbon compounds in FVP which consists of phenolic compounds. This compound affects the recombination of electrons in the valence band and conduction band. The presence of anthocyanins can also increase light adsorption during the photocatalytic process [31].

The morphological features and composition of the $\mathrm{BC}$ and FVP samples were observed by scanning electron microscope/SEM (FEI Quanta FEG 650, USA) and Energy Dispersive X-Ray Spectroscopy/EDS (X-act Oxford). The electron beam in SEM was focused on the point of the sample surface using two condenser lenses. The second condenser lens (or commonly called an objective lens) focuses light with a very small diameter, which is around $10-20 \mathrm{~nm}$. Electron scattering, either Secondary Electron (SE) or Back Scattered Electron (BSE) from the sample surface was detected by the detector and displayed as an image on the screen.

The crystalline structure was conducted to confirm the reaction on the surface of the photocatalyst. The crystallographic properties of the samples were analyzed by X'Pert PRO, X-ray diffraction pattern (Panalytical, Netherlands). The absorbance of the BC and FVP photocatalyst was analyzed using UV-Vis 1601 Spectrophotometer (Shimadzu, Japan). The working principle of spectrophotometry is based on Lambert Beer's law, if monochromatic light passes through a medium, then part of the light is absorbed, a part is reflected, and partly emitted. The amount of light absorbed causes the electron to be excited from the ground state to an excited state which has higher energy.

The functional groups in $\mathrm{BC}$ and FVP were analyzed by IRPrestige 21, Fourier transformation infrared/FTIR (Shimadzu, Japan). The working principle of FTIR is the interaction between energy and matter. Infrared passes through the gap to the sample, where the gap is controlled by the amount of energy sent to the sample. Then some infrared is absorbed by the sample and the rest is transmitted through the surface of the sample. Thus, infrared light passes to the detector and the measured signal is sent to a computer and taken in the form of peaks. The wavelength of halogen lamp irradiation was measured by using Aurora 4000 Fiber Optic Spectrometer (Changchun, China) and analyzed by using Spectral Analysis Software.

To increase hydrogen production, aluminum foil (AF) is inserted into the $\mathrm{BC}$ and $\mathrm{FVP}$ photocatalysts. The positively charged AF [32] assists the catalyst to attract oxygen from the water. At the same time, AF also attracts oxygen from the phenolic compound of FVP which had been disturbed and weakened by $\mathrm{BC}$. Therefore, the bonds between the oxygen and hydrogen in the water are dissociated thereby increasing hydrogen production. The use of these biomass-based photocatalysts is expected to support environmentally friendly energy production for the future.

\section{The aim and objectives of the study}

The study aims to improve hydrogen production by BC, FVP, and AF photocatalysts via water splitting.

To achieve this aim, the following objectives are accomplished:

- analyze the characteristics of the photocatalysts and light source;

- analyze the hydrogen production with BC, FVP, and AF photocatalysts via water splitting; 
- estimate the molecular dynamic energy of the photocatalysts with Hyperchem software;

- examine the stability of photocatalysts in hydrogen production via water splitting.

\section{Materials and methods for hydrogen production by photocatalysts}

$\mathrm{BC}$ and FVP were used as bio-photocatalysts in this study. BC was purchased at the local market in Situbondo, Indonesia. The process of making $\mathrm{BC}$ begins with cutting bamboo stems with a length of $5 \mathrm{~cm}$. Bamboo pieces were cleaned and rinsed with distilled water. The sample was dried in the sun. After that, the samples were carbonized at $600{ }^{\circ} \mathrm{C}$ for 90 minutes. Samples that have become charcoal were refined to a size of 200 mesh. The process was continued by activating charcoal by mixing 30 grams of charcoal with $300 \mathrm{~mL}$ of $\mathrm{NaOH}(2 \%)$ and followed by filtering. The charcoal was kept at room temperature for 12 hours. Then, they were placed in a furnace for 1 hour at $900{ }^{\circ} \mathrm{C}$. After that, they were soaked with $0.1 \mathrm{M} \mathrm{HCl}$ and rinsed with distilled water. The charcoal sample was then dried in an oven at $105^{\circ} \mathrm{C}$. The activation process was repeated 3 times. Activated charcoal that has been formed was stored in a desiccator until it reaches ambient temperature.

FVP was purchased at local markets in Bandung, Indonesia. The process of making FVP begins with soaking strawberries in the water and Heinz ${ }^{\mathrm{TM}}$ white vinegar (5\% acetic acid by volume) at a ratio of 2:1. Strawberry was cut into small sheets with a thickness of $2 \mathrm{~mm}$. The strawberry sheets were dried in a dehydrator for 10 hours. The dried strawberry sheets were mashed to a size of 200 mesh.

$\mathrm{AF}$ was purchased from Malang, Indonesia. The AF material was an 8011 aluminum alloy with a thickness of $0.02 \mathrm{~mm}$ and a diameter of $80 \mathrm{~mm}$. The AF was placed on the bottom of the photocatalytic reactor tube as shown in Fig. 1.
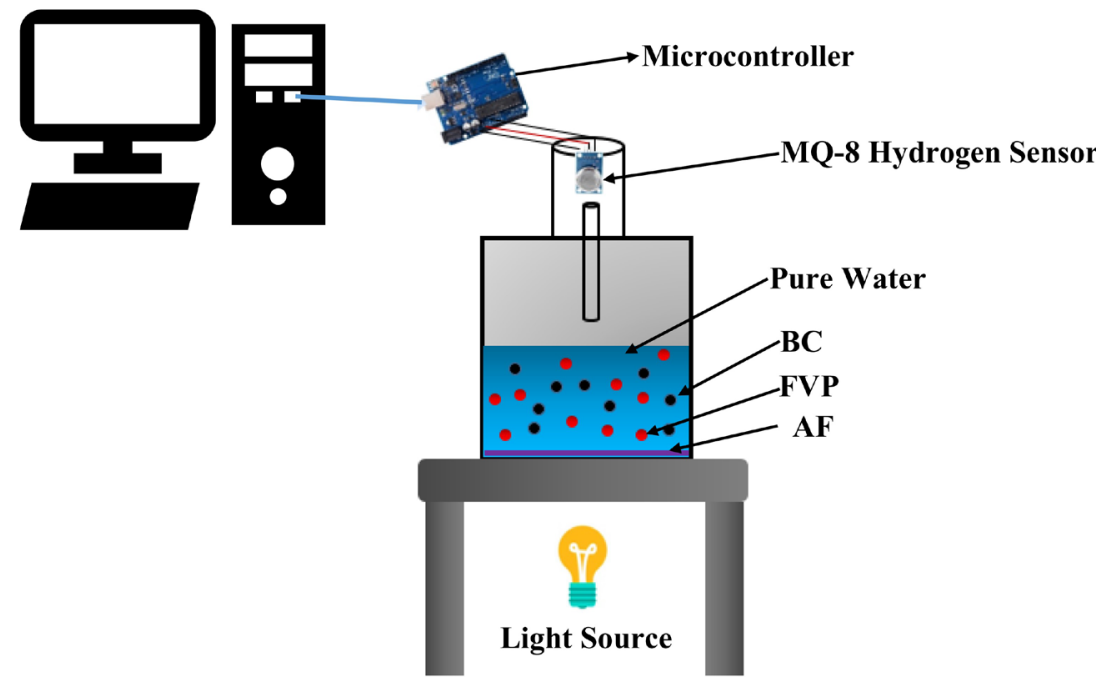

Fig. 1. Experimental apparatus

Fig. 1 shows the experimental apparatus. Hydrogen production was carried out in a closed cylinder reactor with a total volume of $700 \mathrm{~mL}$ filled with $350 \mathrm{~mL}$ of distilled water and the rest is for air. BC and FVP photocatalysts of $5 \mathrm{mg}$ each were dissolved in water. The photocatalytic test was carried out in 5 cycles and each for one hour. The source of light energy uses a $300 \mathrm{~W}$ halogen lamp with a wavelength of $560 \mathrm{~nm}$. The wavelength of the lamp irradiation was measured using the Aurora 4000 Fiber Optic Spectrometer (Changchun, China). The photocatalytic test temperature is maintained at $70{ }^{\circ} \mathrm{C}$. The hydrogen gas produced was measured using the MQ-8 sensor. The MQ-8 sensor has been calibrated with $99.99 \%$ pure hydrogen. The MQ-8 sensor is capable of measuring hydrogen gas in the range of $100-10,000 \mathrm{ppm}$. The working principle of the MQ-8 sensor reading is based on the $R s / R o$ ratio. $R o$ is the initial resistance of the sensor when no hydrogen gas has been detected. Meanwhile, $R s$ is the resistance of the sensor when it detects hydrogen gas. Comparison of Rs/Ro microcontroller connected to computer memory with Arduino Uno software. The hydrogen gas recorded in ppm is converted to $\mu \mathrm{mol} \mathrm{g}^{-1}$.

\section{Results of hydrogen production using BC, FVP,} and AF photocatalysts

\section{1. Characteristics of photocatalysts and light} source

Bamboo charcoal SEM images of BC and FVP are presented in Fig. 2 to give qualitative information on the biomass photocatalyst together with their surface charge in Fig. 3, 4 and Fig. 5, 6 respectively.
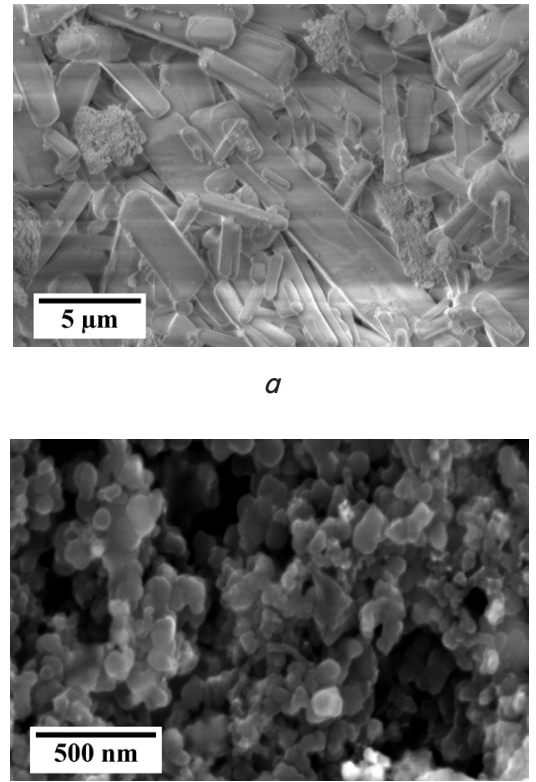

Fig. 2. SEM image: $a-\mathrm{BC} ; b-\mathrm{FVP}$

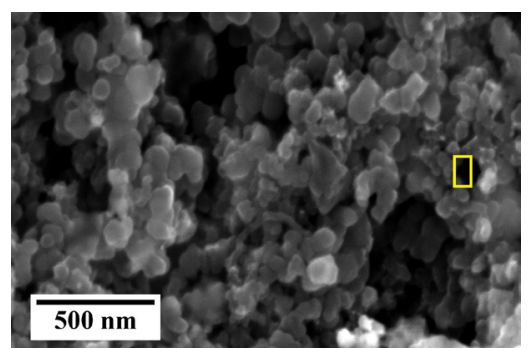

Fig. 3. SEM image of BC. The obser-ved area 

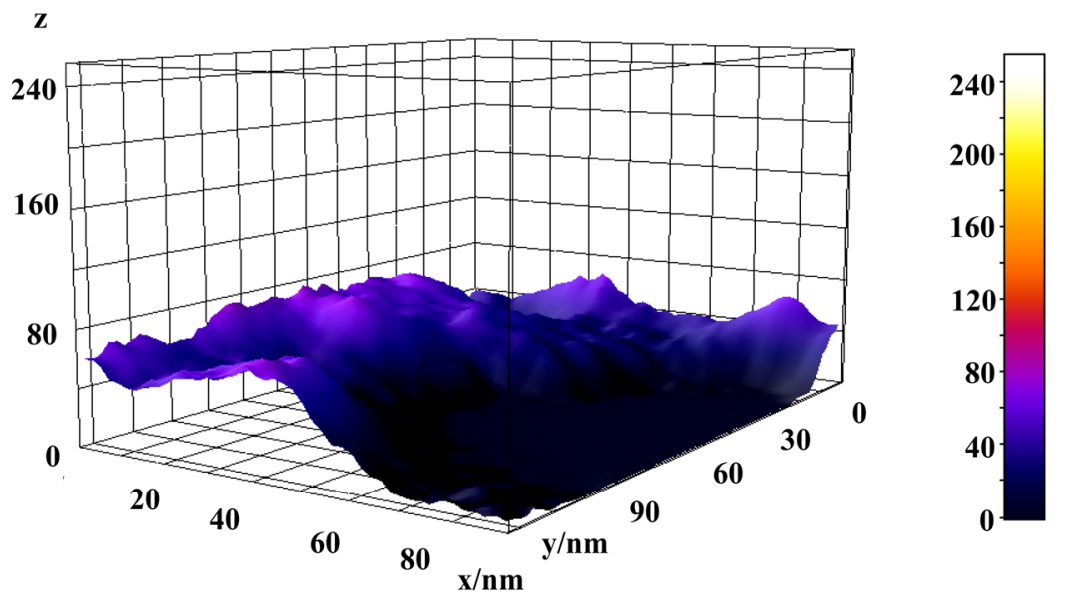

Fig. 4. SEM image of BC. Image J analysis of the observed area

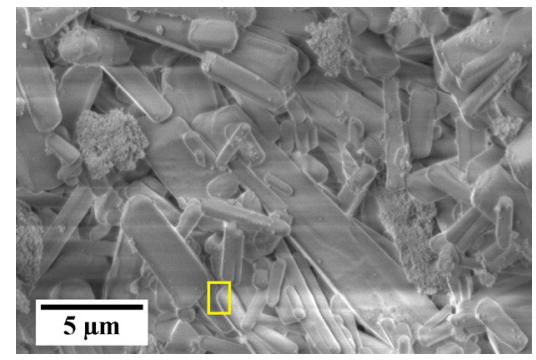

Fig. 5. SEM image of FVP. The observed area

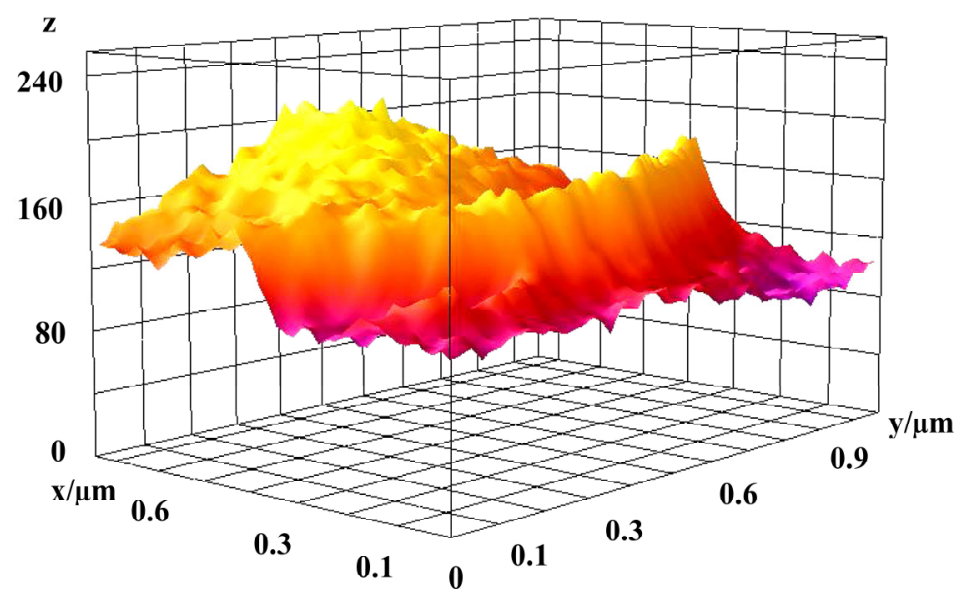

Fig. 6. SEM image of FVP. Image J analysis of the observed area specimen. The black surface indicates that the surface of the specimen is negatively charged so that it rejects electron scattering. Conversely, the yellow to white bright surface color of FVP in Fig. 6 shows that the specimen is positively charged since it attracts electron scattering.

Fig. 7 shows the Energy-Dispersive X-ray Spectroscopy (EDS) results from $\mathrm{BC}$ in weight percent. It can be seen that BC consists of $60.32 \%$ carbon; $9.27 \%$ oxygen; $5.69 \%$ silicone; and $6.92 \%$ potassium; $8.60 \%$ calcium; phosphorus $2.55 \%$; and $6.65 \%$ of $\mathrm{S}, \mathrm{Fe}, \mathrm{Mg}$, $\mathrm{Zn}, \mathrm{Al}, \mathrm{Cl}, \mathrm{Ti}, \mathrm{Cu}, \mathrm{Na}$. These relatively high amounts of calcium and potassium have a role in

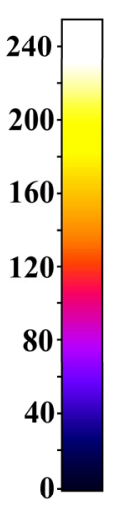
the absorption of photons around the peak of the absorbance wavelength.

Fig. 8 shows the EDS results from the FVP in weight percent. FVP consists of $44.49 \%$ carbon; $46.53 \%$ oxygen; $5.88 \%$ silicone; $3.1 \%$ aluminum. The high elemental oxygen in FVP is a characteristic of phenolic compounds. Also, the presence of the aluminum element increases the absorbance (Fig. 11).

The crystalline structure was observed by using the X'Pert PRO, X-ray diffraction pattern (Panalytical, Netherlands) with $\mathrm{Cu} \mathrm{K}-\alpha_{1}$ radiation $(\lambda=1.54060 \AA), \quad \mathrm{K}-\alpha_{2}$ radiation $(\lambda=1.54443 \AA), \quad \mathrm{K}-\beta$ radiation $(\lambda=1.39225 \AA)$ for a scan rate of ${ }^{\circ} 2 \theta / 0.7 \mathrm{~s}$.

As shown in Fig. 2, $a$, BC has a porous structure whereas FVP (Fig. 2,b) has a cylindrical structure. Fig. 3, 5 show the BC and FVP surfaces analyzed using Image $\mathrm{J}$. The yellow rectangle shows the analyzed BC and FVP surfaces. The color scale consists of black to white. The black scale indicates the negative charge while the white scale indicates a positive charge. The surface color of BC in Fig. 4 is closer to the black scale. So it tends to have a negative charge. This is based on the working principle of SEM, where electrons are scattered onto the

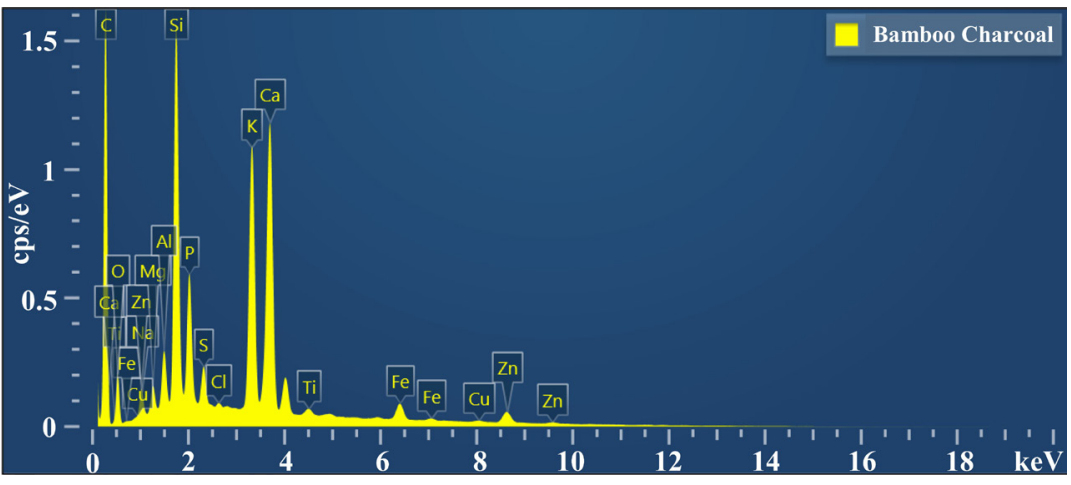

Fig. 7. EDS of $B C$ 


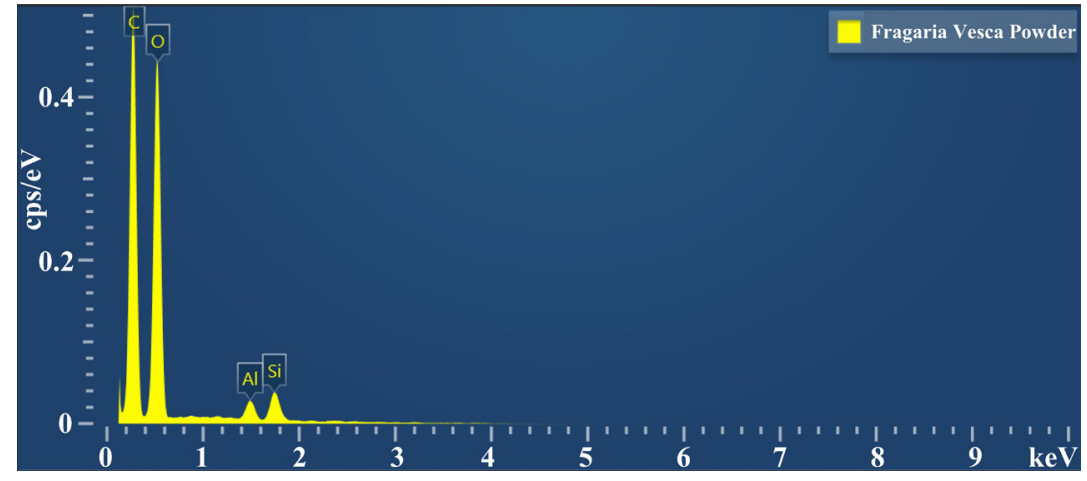

Fig. 8. EDS of FVP

As shown in Fig. 9, $a-c$, peaks of reflected X-ray intensity occur at Bragg angles between $10^{\circ}$ and $30^{\circ}$. The peak intensity of $\mathrm{BC}, \mathrm{FVP}$, and $\mathrm{BC} / \mathrm{FVP}$ is 90 a.u., 125 a.u., and 225 a.u., respectively. This difference in intensity is due to the difference in electron density on the surface of the photocatalyst. When BC/FVP are combined, their intensity increases rapidly. This is because $\mathrm{BC}$ is negatively charged and FVP is positively charged (Fig. 3-6). This positive and negative charge interaction increases electron mobility thereby increasing reflected intensity. Therefore, combined BC/FVP becomes a very active catalyst.

Fig. 10 shows the Fourier-Transform Infrared Spectroscopy (FTIR) result of $\mathrm{BC}$ and FVP. This result is important for identifying the molecular composition in $\mathrm{BC}$ and FVP. As can be seen from Fig. 10, the appearance of peaks at wave numbers of $2,850-2,970 \mathrm{~cm}^{-1}$ and $1,340-1,470 \mathrm{~cm}^{-1}$ indicates the presence of $\mathrm{C}-\mathrm{H}$ alkane groups. The appearance of a peak at a wave number of $3,200-3,600 \mathrm{~cm}^{-1}$ indicates the presence of an $\mathrm{O}-\mathrm{H}$ group. The appearance of a peak at a wave number of 1,610-1,680 $\mathrm{cm}^{-1}$ indicates the presence of a $\mathrm{C}=\mathrm{C}$ alkene group. The appearance of a peak at a wave number of $1,050-1,300 \mathrm{~cm}^{-1}$ indicates the presence of a $\mathrm{C}-\mathrm{O}$ group. The presence of $\mathrm{C}=\mathrm{C}$ alkene groups in $\mathrm{BC}$ and FVP indicates that they form the aromatic structure of the carbon. Besides, the $\mathrm{O}-\mathrm{H}$ group on FVP attracts delocalized electron having to pass through the group. This means that the electron delocalization is getting more energetic.

The absorbance of BC and FVP photocatalysts was analyzed using the UV-Vis 1601 Spectrophotometer (Shimadzu, Japan) giving the result as shown in Fig. 11. The emitted wavelength is in the $200-800 \mathrm{~nm}$ range. The test samples were $\mathrm{BC}, \mathrm{FVP}$, and $\mathrm{BC} / \mathrm{FVP}$, each $100 \mathrm{ppm}$ dispersed in $5 \mathrm{~mL}$ of distilled water. The red line presents the absorbance peak of $\mathrm{BC}$ that occurs at a wavelength of $500 \mathrm{~nm}$. The green line presents the absorbance peak of FVP that occurs at $533 \mathrm{~nm}$. Meanwhile, BC/FVP has two absorbance peaks, one obvious peak at $533 \mathrm{~nm}$ in higher light intensity and the other at $745 \mathrm{~nm}$ with a relatively weak peak. The difference in absorbance peaks is due to $\mathrm{BC}$ consisting of an aromatic carbon ring, while FVP is a phenol compound consisting of an aromatic carbon ring and an $\mathrm{OH}$ functional group. The absorbance of BC is 0.35 a.u. This value is the lowest value of other photocatalysts. The low absorbance of a.u. is due to the very small contact surface area. However, when BC and FVP were combined, the absorbance increased 12 times to 4.2 a.u. This shows that the $\mathrm{OH}$ functional group present in FVP has a significant role in light absorption. Besides, the positive charge of FVP energizes the electron in $\mathrm{BC}$ that absorbs more light energy (Fig. 12).

Fig. 12 shows the results of the spectral analysis on the halogen lamps used as energy sources in photocatalysis in this study. This test is important to estimate how close is the wavelength of the energy source to the wavelength absorbed by photocatalysts. As shown in Fig. 12, the wavelengths of light produced are $560 \mathrm{~nm}$ with an intensity of 14,000 counts.
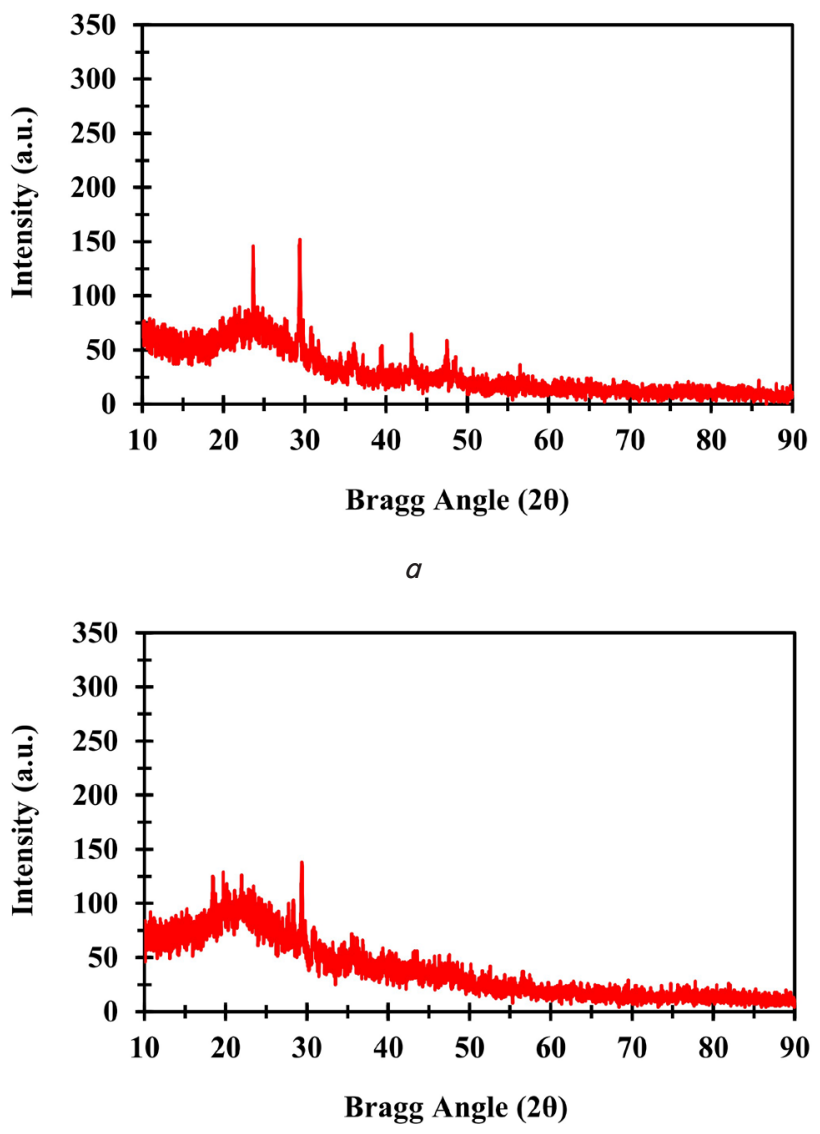

$b$

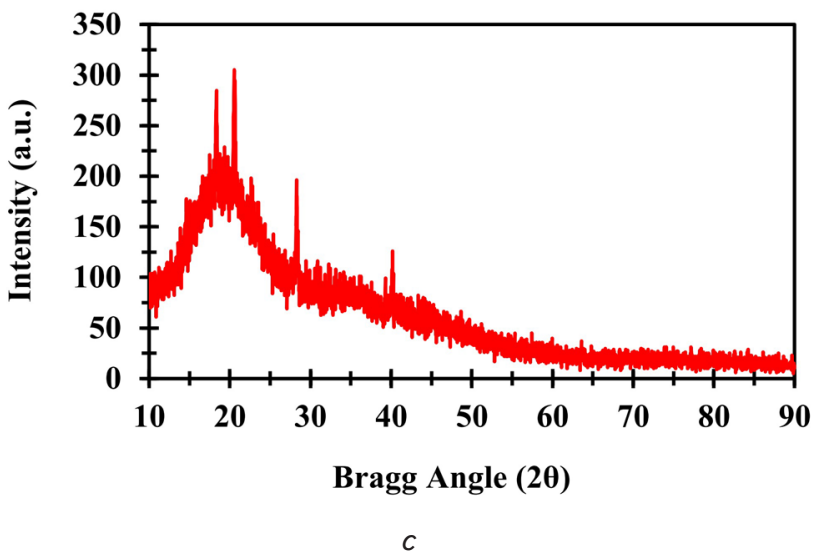

Fig. 9. XRD test result: $a-\mathrm{BC} ; b-\mathrm{FVP} ; c-\mathrm{BC}+\mathrm{FVP}$ 


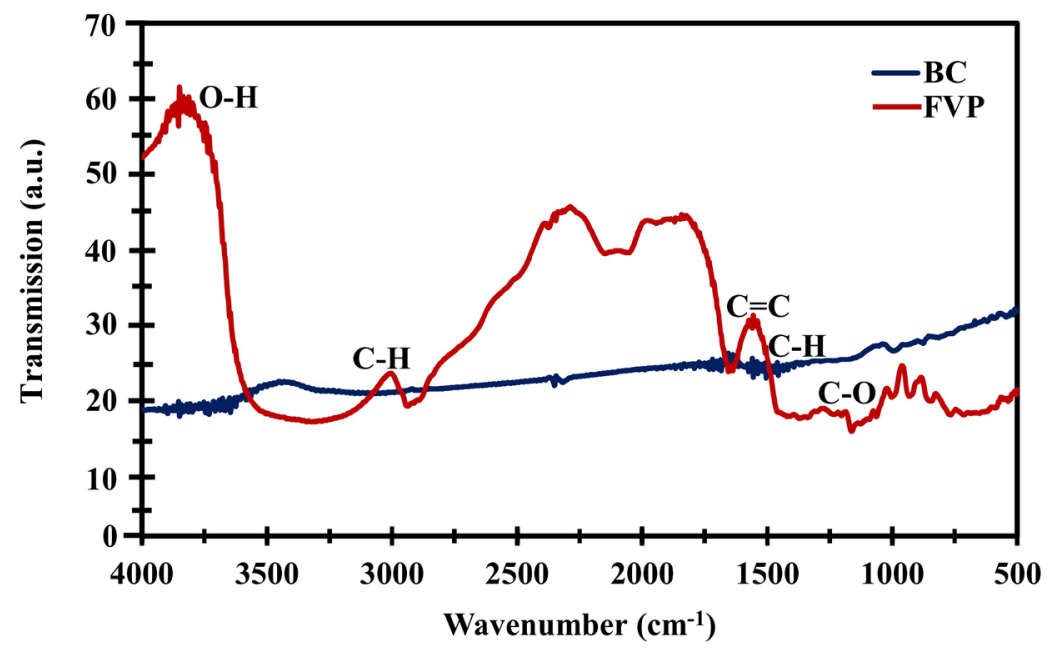

Fig. 10. FTIR test result

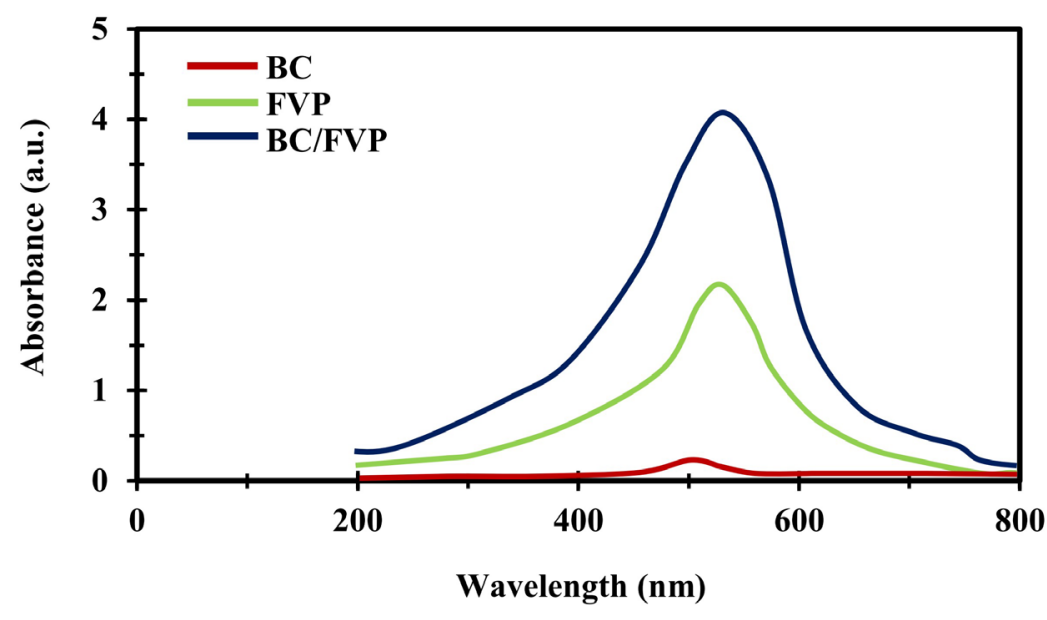

Fig. 11. UV-Vis test result of photocatalysts

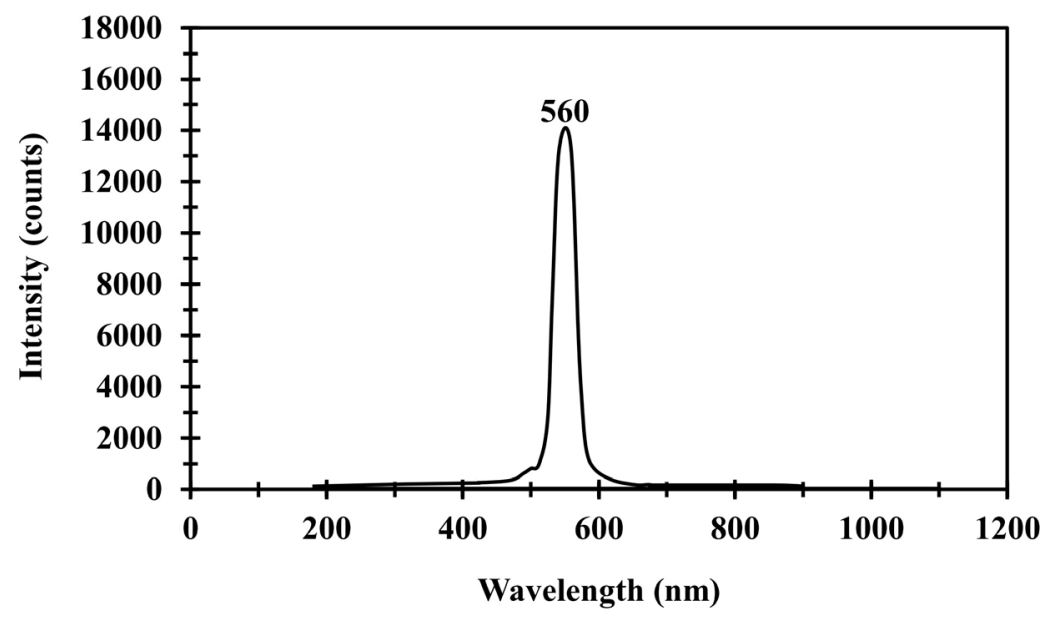

Fig. 12. Spectral analysis of light source

5. 2. Hydrogen production with BC, FVP, and AF photocatalysts via water splitting

Fig. 13, 14 show the test results for various photocatalysts. The photocatalytic process was carried out with a light source from a yellow halogen lamp with a power of $300 \mathrm{~W}$.
The photocatalyst used for BC, FVP each was $5 \mathrm{mg}$. The photocatalytic reactor used has a total volume of $700 \mathrm{~mL}, 350 \mathrm{~mL}$ for distilled water, and the rest for air. The lowest hydrogen production occurs in the BC photocatalyst. Meanwhile, the highest hydrogen production occurred in the combination of $\mathrm{BC} / \mathrm{FVP} / \mathrm{AF}$ photocatalysts. 


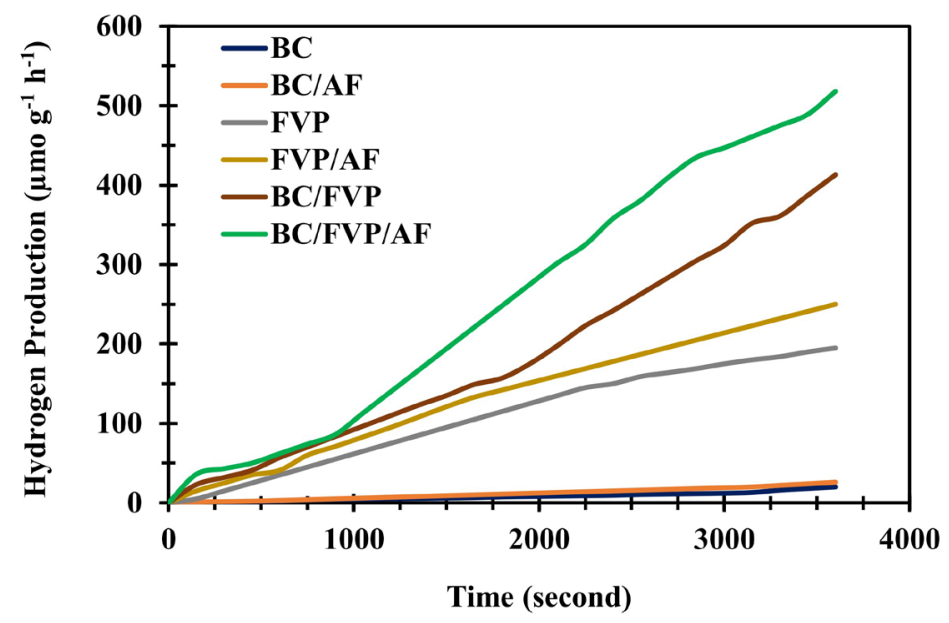

Fig. 13. Hydrogen production with various photocatalysts

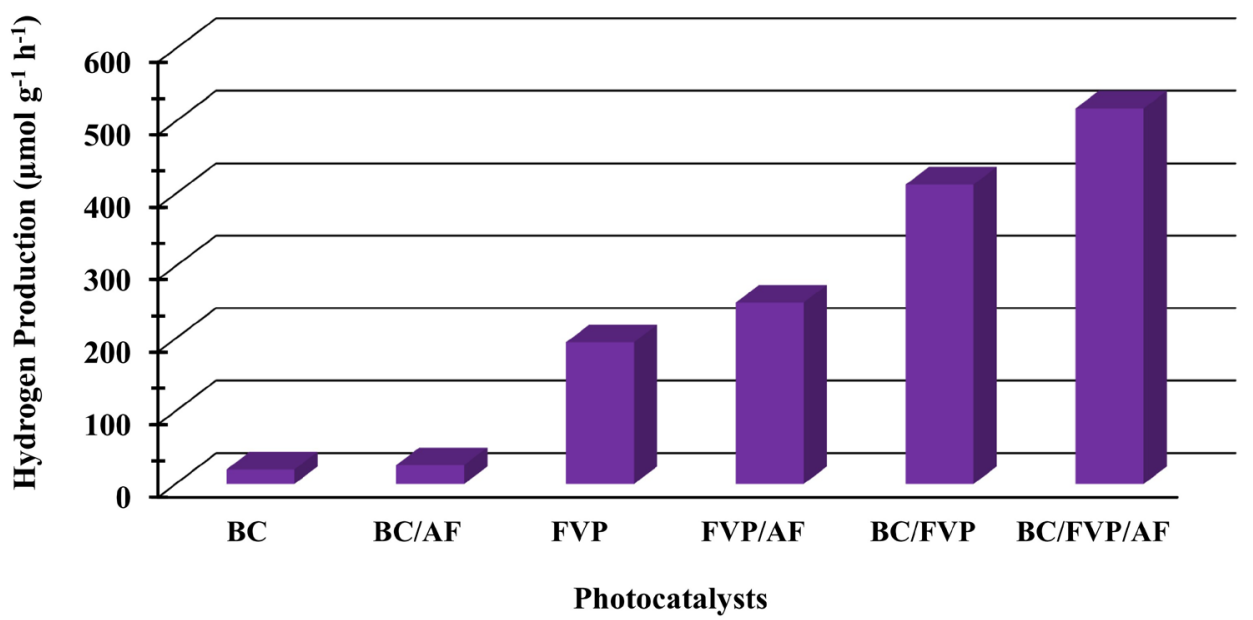

Fig. 14. Histogram of hydrogen production with various photocatalysts

5. 3. Molecular dynamic energy of photocatalysts

Table 1,2 show the molecular dynamic energy of photocatalysts reacted with one water molecule. The molecular dynamic energy was estimated using HyperChem software.

As shown in Table 1, the molecular dynamic energy was estimated at $343 \mathrm{~K}$. The estimation is made by adding a photocatalyst with one water molecule. The BC photocatalyst has a molecular dynamic energy of $107.946 \mathrm{kcal} / \mathrm{mol}$. When $\mathrm{BC}$ and FVP were combined, the molecular dynamic energy increases almost two times.

As shown in Table 2, the molecular dynamic energy was estimated at $343 \mathrm{~K}$. The estimation is made by adding a photocatalyst with one water molecule and aluminum (Al). The $\mathrm{BC}$ and $\mathrm{Al}$ photocatalysts have a molecular dynamic energy of $113.691 \mathrm{kcal} / \mathrm{mol}$. When BC and FVP were combined with $\mathrm{Al}$, the molecular dynamic energy increases almost two times.

\begin{tabular}{|c|c|c|}
\hline Materials & Molecule Structure & $\begin{array}{c}\text { Molecular Dynamic } \\
\text { Energy }(\mathrm{kcal} / \mathrm{mol}) \\
\text { at } 343 \mathrm{~K}\end{array}$ \\
\hline $\mathrm{BC}+\mathrm{H}_{2} \mathrm{O}$ & & 107.946 \\
\hline $\mathrm{FVP}+\mathrm{H}_{2} \mathrm{O}$ & & 109.910 \\
\hline $\mathrm{BC}+\mathrm{FVP}+\mathrm{H}_{2} \mathrm{O}$ & & 206.704 \\
\hline
\end{tabular}


Table 2

Molecular Dynamic Energy with AI

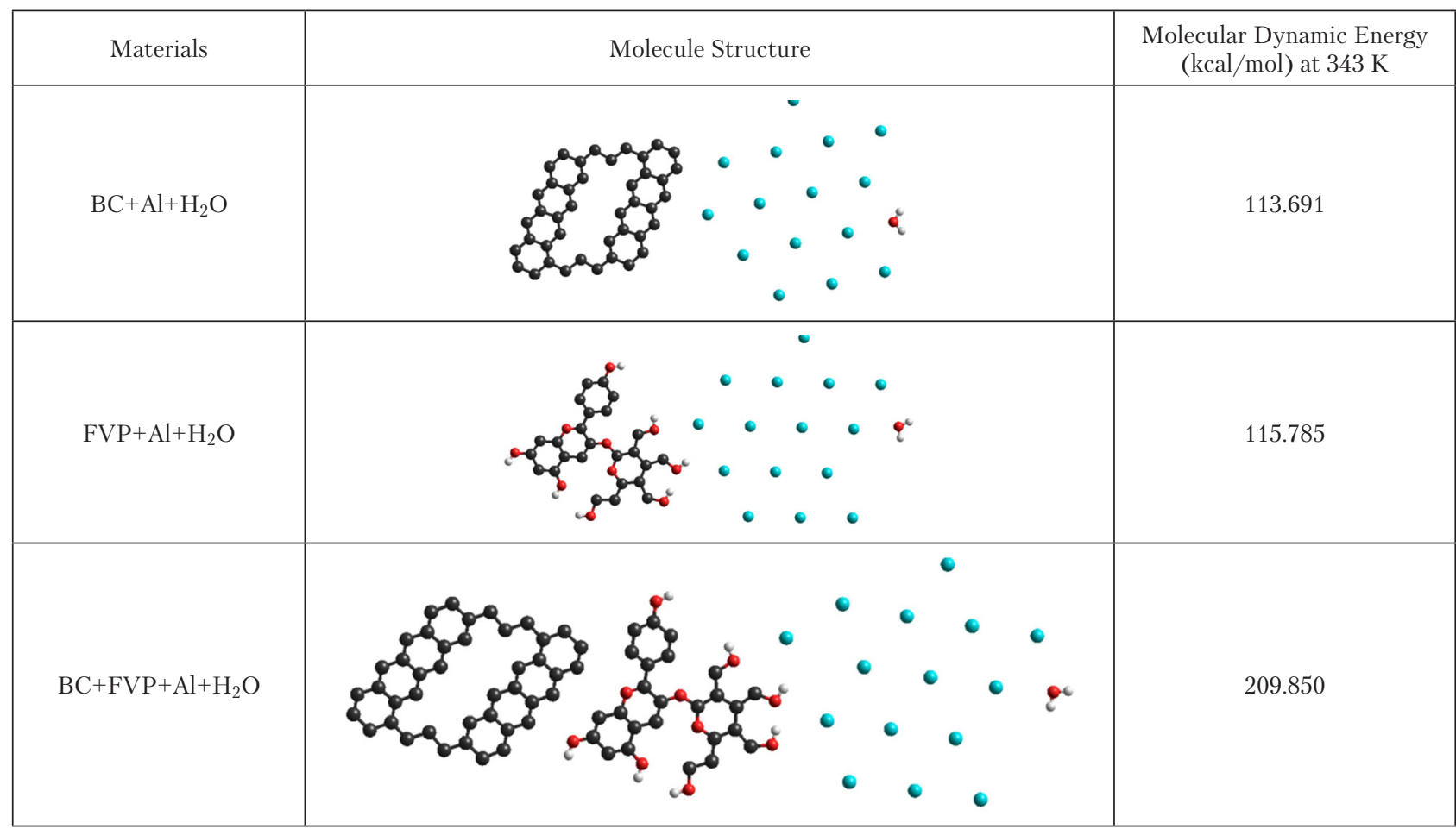

5. 4. Stability of photocatalysts in hydrogen production via water splitting

As shown in Fig. 15, the stability of BC/FVP during the photocatalysis process was examined by repeating the experiment in 5 cycles with 1 hour each.

The reduction in hydrogen gas occurs in about $1.7 \%$ after 5 times the photocatalytic test. The first and fifth cycles produced $522 \mu \mathrm{mol} \mathrm{g}^{-1} \mathrm{~h}^{-1}$ and $513 \mu \mathrm{mol} \mathrm{g}^{-1} \mathrm{~h}^{-1}$ hydrogen gas, respectively. This condition shows that $\mathrm{BC} / \mathrm{FVP}$ have good stability as photocatalysts.

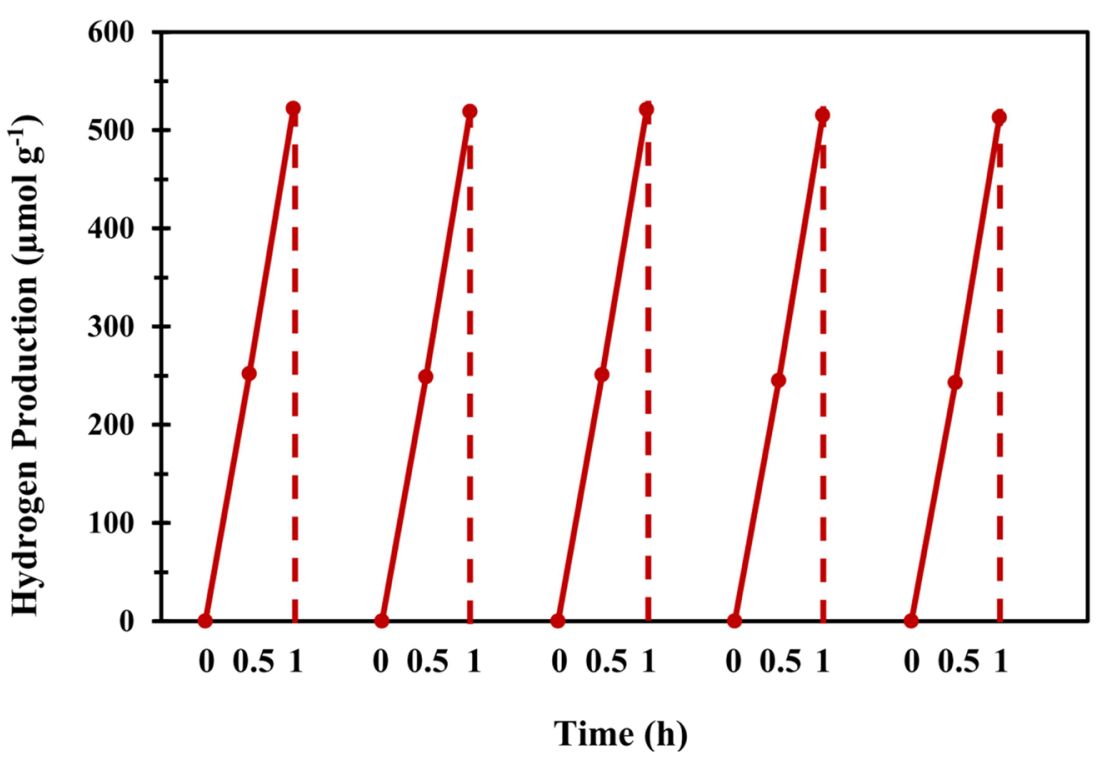

Fig. 15. Stability of photocatalysts

\section{Discussion of hydrogen production mechanism}

6.1. Analysis of hydrogen production by BC, FVP, and $A F$ photocatalysts

Hydrogen production using the $\mathrm{BC}$ photocatalyst was $20 \mu \mathrm{mol} \mathrm{g}^{-1} \mathrm{~h}^{-1}$. This value is directly proportional to the results of the photocatalyst UV-Vis test. The adsorption of $\mathrm{BC}$ is $0.31 \mathrm{a} . \mathrm{u}$. The highest absorbance peak for BC is at a wavelength of $453 \mathrm{~nm}$. From the results of the EDS test, BC is dominated by the element carbon (Fig. 7). Besides, from the FTIR test results, $\mathrm{BC}$ consists of functional groups $\mathrm{C}=\mathrm{C}$, C-H (Fig. 10). This means that BC consists of an aromatic ring of carbon. From the SEM test results, the structure of BC consists of pores which cause the defective aromatic ring. In the aromatic carbon ring, the electrons are delocalized. The delocalization of these electrons produces a magnetic force. If there are many carbon aromatic rings on the $\mathrm{BC}$ surface, there will be an interaction of electromagnetic forces between the aromatic carbon rings. The interaction of these magnetic forces weakens the bonds in the water. Water consists of two bonds, namely a hydrogen bond and a covalent bond. From a strength point of view, covalent bonds are stronger than hydrogen bonds. Therefore, the process of breaking water begins with the breaking of hydrogen bonds by the 
interaction of electromagnetic forces. When the hydrogen bond is broken the covalent bond is weakened and broken by the electromagnetic force of the other aromatic carbon rings.

In the BC and Aluminum Foil (AF) photocatalyst, the hydrogen produced was $26 \mu \mathrm{mol} \mathrm{g}^{-1} \mathrm{~h}^{-1}$. AF with a thickness of $0.016 \mathrm{~mm}$ is placed at the bottom of the reactor tube. The addition of AF leads to an increase in hydrogen production. AF tends to attract oxygen atoms. The presence of $\mathrm{AF}$ facilitates the breaking of the covalent bonds in water, on the other hand the hydrogen and covalent bonds have been weakened by the electromagnetic force in the $\mathrm{BC}$ aromatic ring.

In the FVP photocatalyst, the hydrogen production increased almost 10 times, namely $195 \mu \mathrm{mol} \mathrm{g} \mathrm{g}^{-1} \mathrm{~h}^{-1}$. This condition is directly proportional to the UV-Vis test results, where the highest absorbance is 2 a.u.at a wavelength of $560 \mathrm{~nm}$. This shows that FVP can work optimally when it gets the right energy. FVP is a phenol compound. From the FTIR test results (Fig. 10), FVP consists of $\mathrm{C}-\mathrm{H}, \mathrm{C}=\mathrm{C}, \mathrm{C}-\mathrm{O}$. Apart from that, from the results of the EDS test (Fig. 7, 8), FVP is dominated by the elements of carbon and oxygen.

In FVP and AF photocatalysts, the hydrogen production is $250 \mu \mathrm{mol} \mathrm{g}^{-1} \mathrm{~h}^{-1}$. The addition of AF leads to an increase in hydrogen production. AF tends to attract oxygen atoms and $\mathrm{OH}$ groups in FVP energizing electron in FVP. The presence of AF makes electromagnetic force in the FVP aromatic ring easier to break the covalent bonds in water.

In the combination of $\mathrm{BC}$ and FVP photocatalysts, the hydrogen production increased to $413 \mu \mathrm{mol} \mathrm{g} \mathrm{g}^{-1} \mathrm{~h}^{-1}$. This shows an interaction between $\mathrm{BC}$ and FVP is mutually reinforcing. From the analysis using Image $\mathrm{J}$ software (Fig. 3-6), BC has a negative charge while FVP has a positive charge. From the simulation results with Hyperchem software, the aromatic carbon ring in positively charged FVP tends to be attracted by the negatively charged pores in $\mathrm{BC}$. This interaction energizes the charges both in BC and FVP making them easier to break hydrogen and covalent bonds in water. The stronger positive charge in FVP attracts stronger the negative pole in $\mathrm{O}$ while the stronger negative charge in $\mathrm{BC}$ attracts stronger the positive pole in $\mathrm{H}$ of the water molecule. The stronger opposite attraction of BC and FV P further weakens the water molecule covalent bond. This is what causes hydrogen production to increase up to 2 times when the $\mathrm{BC}$ and FVP photocatalysts are combined.

The combination of $\mathrm{BC}, \mathrm{FVP}$, and $\mathrm{AF}$ supports increased hydrogen production compared to that without AF. In this composition, AF has two important roles, that is, accelerates reduction reaction and facilitates the breaking of the hydrogen and covalent bonds in water. The first role of AF begins when AF energizes electrons in the aromatic rings of $\mathrm{BC}$ and FVP. It makes the jump of electrons from the valence band to the conduction band in $\mathrm{BC}$ and $\mathrm{FVP}$ aromatic ring faster. In the combination of BC and FVP, there are two energy gaps at the wavelengths of 533 and $745 \mathrm{~nm}$ (Fig. 12). When the electrons jump to the conduction band, they will gather first before breaking bonds in water. This condition makes the accumulation of electrons in the conduction band even more. As a consequence, more electrons interact to split the oxygen in the water by a reduction reaction.
The second role, AF which is positively charged attracts oxygen from the water. AF also attracts further oxygen which energizes the FVP carboxyl group which $\mathrm{BC}$ has previously energized. Since the oxygen in the water is attracted by $\mathrm{AF}$ and the interaction of the electromagnetic forces of $\mathrm{BC}$ and $\mathrm{FVP}$, the bonds between oxygen and hydrogen in the water become more dissociated. Each molecule of BC, FVP, AF, and water changes when simulated with the Hyperchem software (Table 2). This means all the electrons are becoming more energetic. Each photocatalyst increases the electron energy so that the hydrogen produced is higher.

As shown in Table 1, the molecular dynamic energy almost doubled when the BC and FVP photocatalysts were combined. This condition indicates a mutual reinforcement by electromagnetic interaction between $\mathrm{BC}$ and FVP. As shown in Table 2, the addition of Al in each photocatalyst also increases the molecular dynamic energy. The position of $\mathrm{BC}$ and FVP changes while AF atoms are more spread indicating that the electrons in $\mathrm{BC}, \mathrm{FVP}$, and $\mathrm{AF}$ are more energetic. AF which is positively charged has a role in attracting oxygen in the water. Besides, AF also attracts oxygen further energizing electron in the FVP carboxyl group which $\mathrm{BC}$ has previously energized. Because the oxygen in water is attracted by more energized FVP and AF, the bonds between oxygen and hydrogen in water are dissociated more.

\section{2. Analysis of photocatalytic mechanism sche-} matic

Fig. 16 shows the photocatalytic mechanism schematic in this study. The energy gap of BC, FVP, and BC/FVP is calculated based on the quantum mechanical energy equation as follows:

\section{Energy $=$ Plank Constant $\times$ Speed of Light/Wavelength.}

The wavelength obtained from the UV-Vis test results is shown in Fig. 16. BC has the highest absorbance peak at a wavelength of $500 \mathrm{~nm}$. Meanwhile, FVP, BC/FVP have the highest absorbance peaks at a wavelength of $533 \mathrm{~nm}$. From the three photocatalysts, BC/FVP has a significant difference in the presence of a second peak at a wavelength of $745 \mathrm{~nm}$. From eq. (1) we get an energy gap of $2.48 \mathrm{eV}$ for $\mathrm{BC}$ and $2.32 \mathrm{eV}$ for FVP, BC/FVP, and $1.66 \mathrm{eV}$ for the second peak at BC/FVP. As shown in Fig. 16, $a$, when BC gets photon energy, the electrons in the valence band will move to the conduction band. This jump produces electron holes in the valence band which causes an oxidation reaction. Whereas in the valence band a reduction reaction occurs. Reduction produces hydrogen gas. On the other hand, when using FVP and BC/FVP photocatalysts, the energy gap decreased to $2.32 \mathrm{eV}$ (Fig. 16, $b, c$ ). It means that the energy required to make electrons moving from the valence band to the conduction band is smaller. Besides, the presence of a second peak at a wavelength of $750 \mathrm{~nm}$ causes some of the electrons in the conduction band to migrate from high potential $(2.32 \mathrm{eV})$ to low potential $(1.66 \mathrm{eV})$. This causes the electron density in the conduction band to increase when compared to BC or FVP photocatalysts. This condition is directly proportional to the production of hydrogen using the $\mathrm{BC} / \mathrm{FVP}$ photocatalyst having the highest value. 


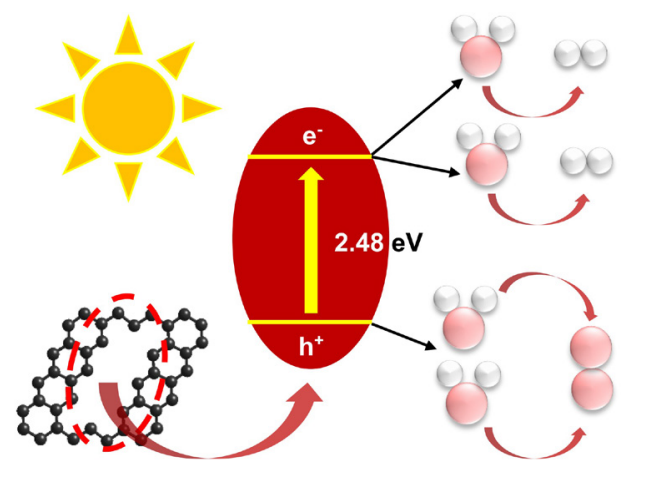

O

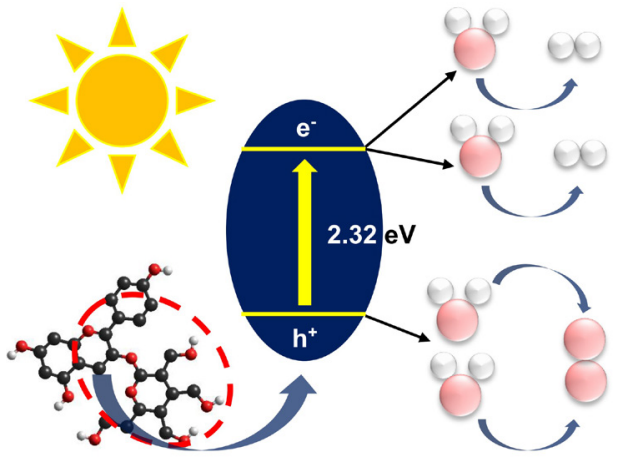

O $\mathrm{H}$

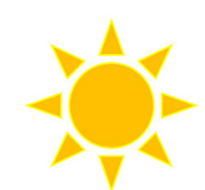

$b$

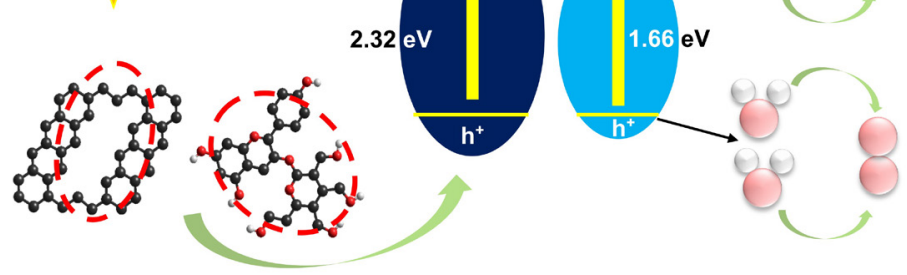

c

Fig. 16. Photocatalytic mechanism schematic: $a-\mathrm{BC} ; b-\mathrm{FVP} ; c-\mathrm{BC}+\mathrm{FVP}$

\subsection{Comparison of the recent} study with previous studies

Table 3 shows the hydrogen results from previous studies. The photocatalysts used generally still use $\mathrm{Pt}, \mathrm{Ni}$, and $\mathrm{Zn}$ metals, while the reaction medium has used biomass such as glycerol, water, rice husks, and olive mill wastewater [31-35]. From previous studies, the highest hydrogen produced was $343 \mu \mathrm{mol} \mathrm{g}^{-1} \mathrm{~h}^{-1}$ using $\mathrm{Pt} / \mathrm{TiO}_{2}$ photocatalyst and the reaction medium in the form of water and olive mill wastewater. The use of biomass materials such as activated carbon and Clitoria ternatea powder can produce relatively significant hydrogen gas [36], 15-480 $\mu \mathrm{mol} \mathrm{g}^{-1} \mathrm{~h}^{-1}$. The light source used was a halogen lamp with a wavelength of $398-633 \mathrm{~nm}$. It shows that carbon compounds have an important role in the process of water splitting by photocatalysts. However, in this study, hydrogen production could reach $518 \mu \mathrm{mol} \mathrm{g}^{-1} \mathrm{~h}^{-1}$ by combining the $\mathrm{BC} / \mathrm{FVP} / \mathrm{AF}$ photocatalysts. BC and FVP each consist of an aromatic ring. However, FVP is a phenol compound that has an $\mathrm{OH}$ group in it. AF has two important roles, i. e., accelerates reduction reaction and facilitates the breaking of the hydrogen and covalent bondsin water.

Table 3

Comparison of the results of previous studies with the recent study

\begin{tabular}{|c|c|c|c|c|}
\hline Photocatalysts & Reaction Medium & Light Source & \begin{tabular}{|c|} 
Hydrogen \\
Production \\
$\left(\mu\right.$ mol g- $\left.^{-1} \mathrm{~h}^{-1}\right)$
\end{tabular} & $\begin{array}{l}\text { Refer- } \\
\text { ences }\end{array}$ \\
\hline $\operatorname{Pt}(0.5 \%) / \operatorname{Au}(3 \%) / W O$ & Glycerol(aq, 2 mM) & $\mathrm{Xe}(450-600 \mathrm{~nm})$ & 132 & [33] \\
\hline $\mathrm{ZnS}$ & $\mathrm{H}_{2} \mathrm{O} /$ glycerol$(\mathrm{l}, 9: 1)$ & $\mathrm{Xe}$ & 232 & [34] \\
\hline $\mathrm{Pt}(0.32 \%) /{ }^{\mathrm{P} 25} \mathrm{TiO}_{2}$ & $\begin{array}{c}\mathrm{H}_{2} \mathrm{O} / \text { ricehusks }(\mathrm{l} / \mathrm{s} \\
0.67 \%)\end{array}$ & UVA (366 nm) & 100 & {$[35]$} \\
\hline $\begin{array}{c}\mathrm{Ni} / \mathrm{LaNiO}_{3-\mathrm{x}}-\mathrm{La}_{2} \mathrm{O}_{2} \\
\mathrm{CO}_{3} \\
\end{array}$ & $\begin{array}{c}\mathrm{H}_{2} \mathrm{O} / \text { formalde- } \\
\text { hyde(l, 8:1) }\end{array}$ & $\mathrm{Xe}(>400 \mathrm{~nm})$ & 35 & {$[36]$} \\
\hline $\mathrm{Pt}(0.5 \%) /{ }^{\mathrm{P} 25} \mathrm{TiO}_{2}$ & $\begin{array}{c}\mathrm{H}_{2} \mathrm{O} / \text { olive mill } \\
\text { wastewater }(1,3.3 \%)\end{array}$ & UVA $(366 \mathrm{~nm})$ & 343 & {$[37]$} \\
\hline $\begin{array}{c}\text { Activated Carbon } \\
\text { Clitoria ternatea powder } \\
\text { Activated carbon+Clito- } \\
\text { ria ternatea powder }\end{array}$ & $\mathrm{H}_{2} \mathrm{O}$ & $\begin{array}{c}\text { Halogen } \\
\text { (398-633nm) }\end{array}$ & $\begin{array}{c}15 \\
150 \\
480\end{array}$ & {$[38]$} \\
\hline $\begin{array}{c}\mathrm{BC} \\
\mathrm{BC} / \mathrm{AF} \\
\mathrm{FVP} \\
\mathrm{FVP} / \mathrm{AF} \\
\mathrm{BC} / \mathrm{FVP} \\
\mathrm{BC} / \mathrm{FVP} / \mathrm{AF}\end{array}$ & $\mathrm{H}_{2} \mathrm{O}$ & $\begin{array}{l}\text { Halogen } \\
(630 \mathrm{~nm})\end{array}$ & $\begin{array}{c}20 \\
26 \\
195 \\
250 \\
413 \\
518\end{array}$ & $\begin{array}{l}\text { Recent } \\
\text { study }\end{array}$ \\
\hline
\end{tabular}


However, this study has limitations in the use of lamps as a light source and BC photocatalyst size. This study did not analyze photocatalysis with sunlight. The light source used is a $300 \mathrm{~W}$ halogen lamp with a wavelength of $560 \mathrm{~nm}$. Moreover, the BC used is still 200 mesh in size. Thus, the photocatalyst is only effective on the surface. This causes hydrogen production with $\mathrm{BC}$ to have the lowest value. It is better if $\mathrm{BC}$ is made in nanosize so that it acts as a photocatalyst maximally. If these two things can be done, the production of hydrogen by photocatalysis completes the original conditions and can be applied applicatively.

\section{Conclusions}

1. BC/FVP has two absorbance peaks. The absorbance increased 12 times to 4.2 a.u. This shows that the $\mathrm{OH}$ functional group present in FVP has a significant role in light absorption. Besides, the positive charge of FVP energizes the electron in $\mathrm{BC}$ that absorbs more light energy.

2. The combination of BC, FVP, and AF supports increased hydrogen production compared to that without AF. In this composition, AF has two important roles, that is, accelerates reduction reaction and facilitates the breaking of the hydrogen and covalent bonds in water.

3. The molecular dynamic energy almost doubled when the BC and FVP photocatalysts were combined. This con- dition indicates a mutual reinforcement by electromagnetic interaction between $\mathrm{BC}$ and $\mathrm{FVP}$. The addition of $\mathrm{Al}$ in each photocatalyst also increases the molecular dynamic energy. AF which is positively charged has a role in attracting oxygen in the water. Besides, AF also attracts oxygen further energizing electron in the FVP carboxyl group which BC has previously energized.

4. The stability of BC/FVP during the photocatalytic process was examined by repeating the experiment in $5 \mathrm{cy}$ cles with 1 hour each. The reduction in hydrogen gas that occurs in about $1.7 \%$ after 5 times the photocatalytic test. The first and fifth cycles produced $522 \mu \mathrm{mol} \mathrm{g}{ }^{-1} \mathrm{~h}^{-1}$ and $513 \mu \mathrm{mol} \mathrm{g}^{-1} \mathrm{~h}^{-1}$ hydrogen gas, respectively. This condition shows that $\mathrm{BC} / \mathrm{FVP}$ have good stability as photocatalysts.

\section{Acknowledgments}

The authors gratefully acknowledge the financial support from the Ministry of Research, Technology, and Higher Education of the Republic of Indonesia (Kementerian Riset Teknologi Dan Pendidikan Tinggi Republik Indonesia) under the PMDSU program with the grant number: $167 / \mathrm{SP} 2 \mathrm{H} / \mathrm{AMD} / \mathrm{LT} / \mathrm{DRPM} / 2020$. This work is also made possible by the Doctoral Program of Mechanical Engineering of the Brawijaya University.

\section{References}

1. Hansen, J., Kharecha, P., Sato, M., Masson-Delmotte, V., Ackerman, F., Beerling, D. J. et. al. (2013). Assessing "Dangerous Climate Change": Required Reduction of Carbon Emissions to Protect Young People, Future Generations and Nature. PLoS ONE, 8 (12), e81648. doi: https://doi.org/10.1371/journal.pone.0081648

2. Ren, R., Zhao, H., Sui, X., Guo, X., Huang, X., Wang, Y. et. al. (2019). Exfoliated Molybdenum Disulfide Encapsulated in a Metal Organic Framework for Enhanced Photocatalytic Hydrogen Evolution. Catalysts, 9 (1), 89. doi: https://doi.org/10.3390/ catal9010089

3. Zhong, Y., Shao, Y., Ma, F., Wu, Y., Huang, B., Hao, X. (2017). Band-gap-matched CdSe QD/WS 2 nanosheet composite: Size-controlled photocatalyst for high-efficiency water splitting. Nano Energy, 31, 84-89. doi: https://doi.org/10.1016/ j.nanoen.2016.11.011

4. Dincer, I., Acar, C. (2015). Review and evaluation of hydrogen production methods for better sustainability. International Journal of Hydrogen Energy, 40 (34), 11094-11111. doi: https://doi.org/10.1016/j.ijhydene.2014.12.035

5. Hibino, T., Kobayashi, K., Ito, M., Nagao, M., Fukui, M., Teranishi, S. (2018). Direct electrolysis of waste newspaper for sustainable hydrogen production: an oxygen-functionalized porous carbon anode. Applied Catalysis B: Environmental, 231, 191-199. doi: https://doi.org/10.1016/j.apcatb.2018.03.021

6. Chua, C. S., Ansovini, D., Lee, C. J. J., Teng, Y. T., Ong, L. T., Chi, D. et. al. (2016). The effect of crystallinity on photocatalytic performance of $\mathrm{Co}_{3} \mathrm{O}_{4}$ water-splitting cocatalysts. Physical Chemistry Chemical Physics, 18 (7), 5172-5178. doi: https://doi.org/ $10.1039 / \mathrm{c} 5 \mathrm{cp} 07589 \mathrm{k}$

7. Tahir, M., Amin, N. S. (2013). Advances in visible light responsive titanium oxide-based photocatalysts for $\mathrm{CO}_{2}$ conversion to hydrocarbon fuels. Energy Conversion and Management, 76, 194-214. doi: https://doi.org/10.1016/j.enconman.2013.07.046

8. Chiarello, G. L., Dozzi, M. V., Scavini, M., Grunwaldt, J.-D., Selli, E. (2014). One step flame-made fluorinated Pt/TiO photocatalysts for hydrogen production. Applied Catalysis B: Environmental, 160-161, 144-151. doi: https://doi.org/10.1016/ j.apcatb.2014.05.006

9. Mu, R., Zhao, Z., Dohnálek, Z., Gong, J. (2017). Structural motifs of water on metal oxide surfaces. Chemical Society Reviews, 46 (7), 1785-1806. doi: https://doi.org/10.1039/c6cs00864j

10. Etacheri, V., Di Valentin, C., Schneider, J., Bahnemann, D., Pillai, S. C. (2015). Visible-light activation of $\mathrm{TiO}_{2}$ photocatalysts: Advances in theory and experiments. Journal of Photochemistry and Photobiology C: Photochemistry Reviews, 25, 1-29. doi: https://doi.org/10.1016/j.jphotochemrev.2015.08.003 
11. Dubey, P. K., Tripathi, P., Tiwari, R. S., Sinha, A. S. K., Srivastava, O. N. (2014). Synthesis of reduced graphene oxide-TiO 2 nanoparticle composite systems and its application in hydrogen production. International Journal of Hydrogen Energy, 39 (29), 16282-16292. doi: https://doi.org/10.1016/j.ijhydene.2014.03.104

12. Chiu, I., Lin, S.-X., Kao, C.-T., Wu, R.-J. (2014). Promoting hydrogen production by loading PdO and Pt on N-TiO ${ }_{2}$ under visible light. International Journal of Hydrogen Energy, 39 (27), 14574-14580. doi: https://doi.org/10.1016/j.ijhydene.2014.07.034

13. Wang, S., Zhu, B., Liu, M., Zhang, L., Yu, J., Zhou, M. (2019). Direct Z-scheme ZnO/CdS hierarchical photocatalyst for enhanced photocatalytic $\mathrm{H}_{2}$-production activity. Applied Catalysis B: Environmental, 243, 19-26. doi: https://doi.org/10.1016/ j.apcatb.2018.10.019

14. Wang, P., Li, H., Sheng, Y., Chen, F. (2019). Inhibited photocorrosion and improved photocatalytic $\mathrm{H}_{2}$-evolution activity of CdS photocatalyst by molybdate ions. Applied Surface Science, 463, 27-33. doi: https://doi.org/10.1016/j.apsusc.2018.08.125

15. Renuka, L., Anantharaju, K. S., Vidya, Y. S., Nagaswarupa, H. P., Prashantha, S. C., Sharma, S. C. et. al. (2017). A simple combustion method for the synthesis of multi-functional $\mathrm{ZrO}_{2} / \mathrm{CuO}$ nanocomposites: Excellent performance as Sunlight photocatalysts and enhanced latent fingerprint detection. Applied Catalysis B: Environmental, 210, 97-115. doi: https://doi.org/10.1016/ j.apcatb.2017.03.055

16. Gao, N., Lu, Z., Zhao, X., Zhu, Z., Wang, Y., Wang, D. et. al. (2016). Enhanced photocatalytic activity of a double conductive $\mathrm{C} / \mathrm{Fe}_{3} \mathrm{O}_{4} / \mathrm{Bi}_{2} \mathrm{O}_{3}$ composite photocatalyst based on biomass. Chemical Engineering Journal, 304, 351-361. doi: https://doi.org/ 10.1016/j.cej.2016.06.063

17. Carrasco-Jaim, O. A., Torres-Martínez, L. M., Moctezuma, E. (2018). Enhanced photocatalytic hydrogen production of $\mathrm{AgMO}_{3}$ $(\mathrm{M}=\mathrm{Ta}, \mathrm{Nb}, \mathrm{V})$ perovskite materials using $\mathrm{CdS}$ and $\mathrm{NiO}$ as co-catalysts. Journal of Photochemistry and Photobiology A: Chemistry, 358, 167-176. doi: https://doi.org/10.1016/j.jphotochem.2018.03.021

18. Ramesh Reddy, N., Bhargav, U., Mamatha Kumari, M., Cheralathan, K. K., Sakar, M. (2020). Review on the interface engineering in the carbonaceous titania for the improved photocatalytic hydrogen production. International Journal of Hydrogen Energy, 45 (13), 7584-7615. doi: https://doi.org/10.1016/j.ijhydene.2019.09.041

19. Roehrich, B. W., Han, R., Osterloh, F. E. (2020). Hydrogen evolution with fluorescein-sensitized Pt/SrTiO 3 nanocrystal photocatalysts is limited by dye adsorption and regeneration. Journal of Photochemistry and Photobiology A: Chemistry, 400, 112705. doi: https://doi.org/10.1016/j.jphotochem.2020.112705

20. Popugaeva, D., Tian, T., Ray, A. K. (2020). Hydrogen production from aqueous triethanolamine solution using Eosin Y-sensitized $\mathrm{ZnO}$ photocatalyst doped with platinum. International Journal of Hydrogen Energy, 45 (19), 11097-11107. doi: https://doi.org/ 10.1016/j.ijhydene.2020.02.055

21. Velázquez, J. J., Fernández-González, R., Díaz, L., Pulido Melián, E., Rodríguez, V. D., Núñez, P. (2017). Effect of reaction temperature and sacrificial agent on the photocatalytic $\mathrm{H}_{2}$-production of $\mathrm{Pt}_{-} \mathrm{TiO}_{2}$. Journal of Alloys and Compounds, 721, 405-410. doi: https://doi.org/10.1016/j.jallcom.2017.05.314

22. Li, Z., Qi, Y., Wang, W., Li, D., Li, Z., Xiao, Y. et. al. (2019). Blocking backward reaction on hydrogen evolution cocatalyst in a photosystem II hybrid Z-scheme water splitting system. Chinese Journal of Catalysis, 40 (4), 486-494. doi: https://doi.org/ 10.1016/s1872-2067(19)63311-5

23. Wu, F., Liu, W., Qiu, J., Li, J., Zhou, W., Fang, Y. et. al. (2015). Enhanced photocatalytic degradation and adsorption of methylene blue via $\mathrm{TiO}_{2}$ nanocrystals supported on graphene-like bamboo charcoal. Applied Surface Science, 358, 425-435. doi: https://doi.org/ 10.1016/j.apsusc.2015.08.161

24. De Cordoba, M. C. F., Matos, J., Montaña, R., Poon, P. S., Lanfredi, S., Praxedes, F. R. et. al. (2019). Sunlight photoactivity of rice husks-derived biogenic silica. Catalysis Today, 328, 125-135. doi: https://doi.org/10.1016/j.cattod.2018.12.008

25. Baharum, N. A., Nasir, H. M., Ishak, M. Y., Isa, N. M., Hassan, M. A., Aris, A. Z. (2020). Highly efficient removal of diazinon pesticide from aqueous solutions by using coconut shell-modified biochar. Arabian Journal of Chemistry, 13 (7), $6106-6121$. doi: https://doi.org/10.1016/j.arabjc.2020.05.011

26. Li, C.-J., Zhao, R., Peng, M.-Q., Gong, X.-L., Xia, M., Li, K. et. al. (2017). Mechanism study on denitration by new PMS modified bamboo charcoal bifunctional photocatalyst. Chemical Engineering Journal, 316, 544-552. doi: https://doi.org/10.1016/ j.cej.2017.01.095

27. Wang, J., Zhang, X., Li, Z., Ma, Y., Ma, L. (2020). Recent progress of biomass-derived carbon materials for supercapacitors. Journal of Power Sources, 451, 227794. doi: https://doi.org/10.1016/j.jpowsour.2020.227794

28. Zhu, J., Jia, J., Tjong, S. C. (2014). Preparation, Structure, and Application of Carbon Nanotubes/Bamboo Charcoal Composite. Nanocrystalline Materials, 1-25. doi: https://doi.org/10.1016/b978-0-12-407796-6.00001-4

29. Pattanayak, S., Loha, C., Hauchhum, L., Sailo, L. (2020). Application of MLP-ANN models for estimating the higher heating value of bamboo biomass. Biomass Conversion and Biorefinery. doi: https://doi.org/10.1007/s13399-020-00685-2

30. Arend, G. D., Adorno, W. T., Rezzadori, K., Di Luccio, M., Chaves, V. C., Reginatto, F. H., Petrus, J. C. C. (2017). Concentration of phenolic compounds from strawberry (Fragaria X ananassa Duch) juice by nanofiltration membrane. Journal of Food Engineering, 201, 36-41. doi: https://doi.org/10.1016/j.jfoodeng.2017.01.014 
31. Buchweitz, M., Speth, M., Kammerer, D. R., Carle, R. (2013). Stabilisation of strawberry (Fragaria x ananassa Duch.) anthocyanins by different pectins. Food Chemistry, 141 (3), 2998-3006. doi: https://doi.org/10.1016/j.foodchem.2013.04.117

32. Zani, M., Sala, V., Irde, G., Pietralunga, S. M., Manzoni, C., Cerullo, G. et. al. (2018). Charge dynamics in aluminum oxide thin film studied by ultrafast scanning electron microscopy. Ultramicroscopy, 187, 93-97. doi: https://doi.org/10.1016/j.ultramic.2018.01.010

33. Tanaka, A., Hashimoto, K., Kominami, H. (2014). Visible-Light-Induced Hydrogen and Oxygen Formation over Pt/Au/ $/ \mathrm{WO}_{3}$ Photocatalyst Utilizing Two Types of Photoabsorption Due to Surface Plasmon Resonance and Band-Gap Excitation. Journal of the American Chemical Society, 136 (2), 586-589. doi: https://doi.org/10.1021/ja410230u

34. Bao, D., Gao, P., Zhu, X., Sun, S., Wang, Y., Li, X. et. al. (2015). ZnO/ZnS Heterostructured Nanorod Arrays and Their Efficient Photocatalytic Hydrogen Evolution. Chemistry - A European Journal, 21 (36), 12728-12734. doi: https://doi.org/10.1002/ chem.201501595

35. Speltini, A., Sturini, M., Dondi, D., Annovazzi, E., Maraschi, F., Caratto, V. et. al. (2014). Sunlight-promoted photocatalytic hydrogen gas evolution from water-suspended cellulose: a systematic study. Photochemical \& Photobiological Sciences, 13 (10), 1410-1419. doi: https://doi.org/10.1039/c4pp00128a

36. Jia, L., Li, J., Fang, W. (2010). Effect of $\mathrm{H}_{2} / \mathrm{CO}_{2}$ mixture gas treatment temperature on the activity of $\mathrm{LaNiO}_{3}$ catalyst for hydrogen production from formaldehyde aqueous solution under visible light. Journal of Alloys and Compounds, 489 (2), L13-L16. doi: https://doi.org/10.1016/j.jallcom.2009.09.104

37. Speltini, A., Sturini, M., Maraschi, F., Dondi, D., Fisogni, G., Annovazzi, E. et. al. (2015). Evaluation of UV-A and solar light photocatalytic hydrogen gas evolution from olive mill wastewater. International Journal of Hydrogen Energy, 40 (12), 4303-4310. doi: https://doi.org/10.1016/j.ijhydene.2015.01.182

38. Sofi'i, Y. K., Siswanto, E., Winarto, Ueda, T., Wardana, I. N. G. (2020). The role of activated carbon in boosting the activity of clitoria ternatea powder photocatalyst for hydrogen production. International Journal of Hydrogen Energy, 45 (43), $22613-22628$. doi: https://doi.org/10.1016/j.ijhydene.2020.05.103 